\section{EDUCAÇ̃̃O}

Número Temático - vol. 9 n. 3 - 2020

ISSN Digital: 2316-3828

ISSN Impresso: 2316-333X

DOI: 10.17564/2316-3828.2020v9n3p9-26

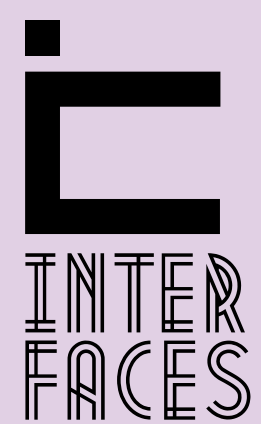

CIENTÍFICAS

\title{
PEDAGOGIA INTEGRADORA: SINALIZAÇÕES DIDÁTICO-CURRICULARES PARA EXPERIÊNCIAS DE EDUCAÇ̃̃O INTEGRAL
}

\author{
INTEGRATOR PEDAGOGY: DIDACTIC-CURRICULAR SIGNALS FOR \\ INTEGRAL EDUCATION EXPERIENCES
}

\section{PEDAGOGIA INTEGRADORA: SEÑALES DIDACTICO-CURRICULARES PARA EXPERRENCIAS DE EDUCACIÓN INTEGRAL}

José Leonardo Rolim de Lima Severo ${ }^{1}$ Dinora Tereza Zucchetti ${ }^{2}$

\section{NÚMERO TEMÁTICO}

"PEDAGOGIA INTEGRADORA: SABERES E MODOS DE AÇÃO"

\section{RESUMO}

O objetivo do artigo é demarcar o significado conceitual para a expressão Pedagogia Integradora, assumindo-a como um mote para problematizar a ampliação dos tempos e espaços formativos em experiências de Educação Integral que articulam aspectos escolares e não escolares. Buscamos identificar que a Educação Integral demanda a construção de uma Pedagogia Integradora orientada por proposições didático-curriculares que visem superar antagonismos entre saberes e modos de ação surgidos da dicotomização entre o aprender na escola e fora dela. As assertivas teóricas se aliam à análise de dados de uma pesquisa de Educação Comparada Intranacional para explorar o desenvolvimento do Projeto Político-Pedagógico e do Currículo em quatro escolas no Rio Grande do Sul. O texto aponta que as agendas escolares de Educação Integral são materializadas por novos arranjos de formação que, apesar de ter se ampliado em termos de pluralização de experiências, enfrentam desafios para romper a dicotomia que existe entre o aprender em sala de aula, que se delineia em torno de conteúdos fortemente disciplinarizados, e o que se aprende fora dela, por meio de outras dinâmicas institucionais. Na construção de uma Pedagogia Integradora, as escolas se veem diante da possibilidade de investir em mediações didáticas que dinamizem a relação dos sujeitos com os saberes e experiências formativas, visando abranger dimensões do desenvolvimento individual e coletivo que atendam ao princípio da integralidade.

\section{PALAVRAS-CHAVE}

Pedagogia Integradora. Educação Integral. Currículo. Didática. 


\section{RESUMEN}

El objetivo de este artículo es demarcar el significado conceptual de la expresión Pedagogía Integradora, asumiéndolo como un fundamento para problematizar la expansión de los tiempos y espacios formativos en experiencias de Educación Integral que articulan aspectos escolares y no escolares. Buscamos identificar que la Educación Integral exige la construcción de una Pedagogía Integradora guiada por proposiciones didáctico-curriculares que tengan como objetivo superar los antagonismos entre el conocimiento y los modos de acción que surgen de la dicotomía que se hace entre el aprendizaje en la escuela y fuera de ella. Las asertivas teóricas se combinan con el análisis de datos de una investigación de Educación Comparada Internacional para explorar el desarrollo del Proyecto político-pedagógico y el plan de estudios en cuatro escuelas de Rio Grande do Sul. El texto señala que las agendas escolares de la Educación Integral se materializan por nuevas estructuras que, aunque se hayan expandido en términos de la pluralización de experiencias, se enfrentan a desafíos para romper la dicotomía que existe entre el aprendizaje en el aula, que se delinea en torno a contenido fuertemente disciplinado, y lo que se aprende fuera de él, a través de otras dinámicas institucionales. En la construcción de una Pedagogía Integradora, las escuelas enfrentan la posibilidad de invertir en mediaciones didácticas que dinamizan la relación de los sujetos con el conocimiento y las experiencias formativas, con el objetivo de abarcar dimensiones de desarrollo individual y colectivo que cumplan con el principio de integralidad.

\section{PALABRAS CLAVE}

Pedagogía Integrativa. Educación integral. Curriculum. Didáctica

\section{ABSTRACT}

The objective of this paper is to demarcate the conceptual meaning for the expression Integrative Pedagogy, assuming it as a foundation to problematize the expansion of times and spaces in Integral Education experiences that articulate school and non-school aspects. We seek to identify that Integral Education demands the construction of an Integrative Pedagogy guided by didactic-curricular propositions that aim to surpass antagonisms between knowledge and modes of action arising from the dichotomization between learning at school and outside it. The theoretical assertions combine with the data analysis of an Intranational Comparative Education research to explore the development of the Political-Pedagogical Project and the Curriculum in schools in four Rio Grande do Sul. The text points out that the school agendas of Integral Education are materialized by new arrangements of formation that, even though they have expanded in terms of the pluralization of experiences, they 
face challenges in breaking the dichotomy that exists between learning in the classroom, which is delineated around strongly disciplined content, and what is learned outside it, through other institutional dynamics. In the construction of an Integrative Pedagogy, schools are faced with the possibility of investing in didactic mediations that streamline the subjects' relationship with knowledge and formative experiences, aiming to include dimensions of individual and collective development that comply with the principle of integrality.

\section{KEYWORDS}

Integrative Pedagogy. Integral Education. Curriculum. Didactic.

\section{INTRODUCÇÃO}

A Pedagogia contemporânea é palco de muitas perspectivas educacionais que apostam no princípio da integração de saberes e recursos de aprendizagem, bem como de tempos e espaços educativos, na integralidade do sujeito etc. A ideia de que as práticas pedagógicas necessitam criar cenários e oportunidades integrais, integradoras e integrativas ou integralizantes representa um aspecto central do discurso sobre transformação do sentido atribuído à formação humana e sobre a inovação didática e curricular em experiências escolares e não escolares.

No campo da escolarização, as políticas públicas têm investido na ampliação dos tempos e espaços formativos a partir de iniciativas de indução e institucionalização da Educação Integral e o Plano Nacional de Educação para o período de 2014-2024 (BRASIL, 2014) a constituiu como meta estratégica vinculada à concretização do Direito à Educação. Sejam em escolas em que a jornada foi ampliada por meio de programas extracurriculares como o Mais Educação e o Novo Mais Educação ou em escolas com agenda institucional específica de Educação Integral em Tempo Integral, os projetos político-pedagógicos e curriculares têm sido provocados pela articulação de saberes e experiências escolares e não escolares.

Isso se opera mediante o que se poderia denominar como desterritorialização pedagógica que consiste em um processo curricular de mediações que tornam possível o diálogo entre saberes escolarizados e saberes da formação humana atrelados a outros modos de socialização tradicionalmente deslocados do espaço da escola. Trata-se de processos de apropriação de espaços de sociabilidade que geram o diálogo ente a escola e outras instâncias educativas (BRASIL, 2009).

Tal processo é capaz de criar objetos e relações de aprendizagem que ressignificam o espaço escolar por meio de um fluxo dinâmico que insere na escola em uma rede de possibilidades capazes de oportunizar a concretização de um projeto formativo centralmente definido pela complexidade e transversalidade dos saberes na perspectiva da Educação Integral, mediante não apenas a ampliação do tempo escolar, mas sobretudo pela qualificação do mesmo como tempo de aprendizagens em que 
os saberes e experiências cujas raízes se encontram fora das escolas possam dialogar e ampliar o espectro do currículo e dos projetos institucionais desenvolvidos por elas.

O sentido da Pedagogia Integradora estaria no reconhecimento que a incorporação desses saberes e experiências que dilatam os projetos e currículos escolares necessita ser subsidiada por formas de articulação mais orgânicas e dinâmicas, uma vez que não é incomum que escolas com jornada ampliada ou com propostas específicas de Educação Integral invistam em modos de organização que dicotomizam a "aprendizagem em sala de aula" dos chamados "projetos extra-classe”.

Essa dicotomia, por sua vez, alimenta representações didático-curriculares que fazem com que tais saberes e experiências, por não estarem integrados ao trabalho docente em sala de aula, tenham menos importância em face da hierarquização de conhecimentos e competências feita por docentes e gestores(as), em grande medida estimulada por tendências de avaliação de qualidade da escola que acionam estratégias de testagem de proficiência, ranqueamento e responsabilização por resultados.

Como o "extra-classe" não pauta as avaliações externas, a escola se converte em espaço em que hierarquias de experiências formativas se constroem e se justificam em razão de critérios de compatibilidade entre o aprendido pelos(as) estudantes e o testado pelos organismos de controle a regulação das políticas curriculares.

Com este artigo, pretende-se projetar um debate que se encontra em fase inicial de estruturação conceitual sobre a Pedagogia Integradora, assinalando assertivas teórico-metodológicas e suas implicações no modo como se concebe e se organizam as experiências de Educação Integral na Escola de Tempo Integral, reconhecendo, como plano de fundo, a problemática de que se os tempos e espaços escolares ampliados na perspectiva do tempo integral não forem concebidos como uma dilatação que exige a criação de redes orgânicas de saberes e experiências nos "entrelugares", a cisão sala de aula/ambientes escolares/territórios comunitários transportará, outra vez, diversas oportunidades formativas para o campo do não escolar.

\section{EDUCAÇÃO INTEGRAL E PEDAGOGIA INTEGRADORA}

Considerar a Educação Integral como paradigma formativo requer diferenciá-la, desde logo, de escola em tempo integral ou jornada ampliada, além de situá-la no contexto de uma sociedade pedagógica, em que as pessoas estão inseridas em múltiplas redes educativas escolares e não escolares, nas quais constroem relações de aprendizagem na interface com seus cotidianos comunitários, laborais, comunicacionais etc., como base de uma trajetória de educação ao longo da vida.

O tempo integral ou jornada ampliada são dispositivos de organização escolar acionados para implementar projetos pedagógico-curriculares que envolvem uma maior carga horária de atividades de ensino-aprendizagem nas escolas. Uma primeira aproximação ao conceito de Pedagogia Integradora envolve justamente esse movimento de compreensão sobre como diferentes dimensões do desenvolvimento humano e social se conectam em uma escola de tempo integral ou jornada ampliada, pois, em si, esses dispositivos não asseguram a concretização da Educação Integral como paradigma 
formativo. Ou seja, “[...] de nada adiantará esticar a corda do tempo: ela não redimensionará, obrigatoriamente, esse espaço. E é, nesse contexto, que a educação integral emerge como uma perspectiva capaz de re-significar os tempos e os espaços escolares" (MOLL, 2003, p. 18).

Na perspectiva da Educação Integral, a escola é compreendida como um espaço-tempo de potencialização das aprendizagens que constituem estudantes e professores(as) como sujeitos cujo desenvolvimento integra dimensões cognitivas, sociais e emocionais, e de articulação entre diferentes contextos em que essas aprendizagens se dão, como as salas de aula, quadras, espaços de convivência da escola, entorno comunitário, a cidade como instância educativa e seus aparatos culturais (parques, praças, museus, igrejas, cinemas etc.).

Gadotti (2009) ressalta que esse paradigma deve ser almejado por todas as escolas, inclusive as que não funcionam em tempo integral ou em jornada ampliada, pois professores(as) e equipes pedagógicas necessitam promover múltiplas oportunidades de aprendizagem para os(as) estudantes, recorrendo a estratégias inventivas referenciadas em critérios de qualidade sociocultural que mobilizem seus potenciais individuais e coletivos para produzirem conhecimento e práticas que levem à mudança das condições existenciais.

Ao discorrer sobre o princípio da integralidade como elemento central da Educação Integral, o autor problematiza que "[...] uma educação integral é uma educação com qualidade sociocultural. A integração da cultura, da saúde, do transporte, da assistência social etc. com a educação possibilita a integralidade da educação (GADOTTI, 2009, p. 98).

A Educação Integral está presente em formulações e experiências promovidas por educadores brasileiros como Anísio Teixeira, com a Escola Parque na década de 1960 em Salvador, Darcy Ribeiro, com os Centros Integrados de Educação Pública (CIEP) na década de 1980 no Rio de Janeiro. Na década de 1990, no Rio Grande do Sul, no Governo de Alceu Colares os CIEP, tal qual no Rio de Janeiro seguiam os auspícios da bandeira para a educação do Partido Democrático Trabalhista (PDT). No mesmo período em nível nacional poucos Centros de Atenção Integral à Crianças (CAIC) foram implementados no governo de Fernando Collor.

Tratou-se de experiências inovadoras que articularam a oferta de serviços escolares a serviços socioassistenciais, visando garantir oportunidade de acesso à direitos sociais por segmentos populacionais em situação de pobreza, referenciando na escola demandas de promoção do desenvolvimento humano e social em uma perspectiva ampla de aprendizagem e inclusão. Entretanto, foram experiências que não se desdobraram para outras regiões do país e se limitaram ao incentivo técnico-financeiro passageiro de governos locais, visto que "[...] propostas de incentivo a uma escola de tempo integral nunca tiveram continuidade e legitimidade na política pública educacional brasileira" (CAMARGO; SARTURI; TREVISAN, 2019, p. 224).

Foi em 2007, com a criação do Programa Mais Educação (PME), que a Educação Integral passa a ocupar lugar de destaque na agenda política. Por meio do PME, os(as) estudantes tiveram a oportunidade de participar de diferentes atividades extraclasse, no turno inverso ao da sua matrícula regular, envolvendo linguagens artísticas, esportes etc. O PME serviu como estratégia indutora de experiências de Educação Integral no país, pautando-se por indicadores sociais e educacionais para a seleção de escolas participan- 
tes e na aplicação de investimentos, de modo a priorizar, portanto, crianças, adolescentes e jovens pobres e escolas com baixo desempenho no Índice de Desenvolvimento da Educação Básica (IDEB).

A abrangência do programa foi restrita e o seus objetivos limitaram-se em 2015, quando suas diretrizes são reformuladas e passa a ser denominado de Programa Novo Mais Educação (PNME), contemplando prioritariamente, a partir de então, reforço escolar nas áreas de Língua Portuguesa e Matemática.

Assim como em seus primórdios, com as iniciativas de Anísio Teixeira e Darcy Ribeiro, as experiências de jornada ampliada e tempo integral, a exemplo do PME e do PNME, têm se voltado à oferta de oportunidades educativa em cenários sociais marcados por profundas desigualdades de acesso da população à direitos básicos.

A escola se constitui como uma instituição "porta de entrada" de muitos sujeitos na estrutura dos serviços públicos, com significativa capilaridade nos territórios comunitários. Essa circunstância faz dela um elemento estratégico na construção de agendas intersetoriais pelo Estado, a fim de implementar, em conjunto com os objetivos próprios da escolarização, uma pauta civilizatória mais ampla que deve ser fundamentada no ideal da justiça social, como assinalam Leclerc e Moll (2012, p.17) quando situam que, diante das desigualdades estruturantes do nosso país e dos mecanismos de exclusão ligados às diferenças, “[...] a construção de uma política de educação básica de tempo integral faz parte das políticas afirmativas e de enfrentamento de desigualdades".

Depreende-se que a Educação Integral na escola em tempo integral se configura como uma estratégia política de enfrentamento a desigualdades ligadas à falta de oportunidades de acesso e qualidade de permanência de estudantes na escola, as quais alimentam diretamente mecanismos de exclusão social. Com a expansão das possibilidades de aprendizagem proporcionadas pelo tempo integral, se pode projetar estratégias que colaborem para a garantia do direito à educação como direito a aprender e a se desenvolver na escola.

0 direito à educação é uma prerrogativa para efetivação e ampliação das garantias fundamentais às pessoas em uma sociedade democrática e a escola em tempo integral na perspectiva da Educação Integral pode materializar esse direito quando atua de maneira intersetorial e com foco nas múltiplas condições que levam ao pleno desenvolvimento da pessoa, conforme expresso no artigo 205 da Constituição Federal (BRASIL, 1988).

A intersetorialidade como princípio do planejamento e da implementação de experiências de Educação Integral em Tempo Integral se desdobra por meio da [...] articulação entre Educação, Assistência Social, Cultura e Esporte, dentre outras políticas públicas [...] como uma importante intervenção para a proteção social, prevenção a situações de violação de direitos. (BRASIL, 2009, p. 25).

Em consonância com o artigo 205 da Constituição Federal e artigo $34^{\circ}$ da Lei de Diretrizes e Bases da Educação Nacional (BRASIL, 1996), o qual estipula que o ensino fundamental deverá ser ofertado progressivamente em tempo integral, o Plano Nacional de Educação instituído pela Lei 13.005/2014 (BRASIL, 2014) para o decênio 2014-2024 prevê, por meio da meta n. 6, que 50\% das escolas funcionem na modalidade de tempo integral para atenderem a $25 \%$ dos alunos(as) da Educação Básica.

Essa previsão está distante de se efetivar, tendo em vista os cortes orçamentários que comprometem, concretamente, a aplicação de recursos e as articulações intersetoriais necessárias à gestão das escolas e o desenvolvimento curricular. De acordo com dados do Instituto Nacional de Estudos e Pesquisas Educa- 
cional (INEP), apenas no ano de 2016 as matrículas em tempo integral caíram 47\% e, apesar de em 2017 o índice ter voltado a crescer para 15,3\%, o percentual ainda está abaixo do dos anos de 2014 e 2015.

Na perspectiva da Educação Integral, a sala de aula não é o único espaço de desenvolvimento curricular, o que supõe a ressignificação da própria noção de currículo e de aprendizagem sob a crítica às tradições disciplinarizantes que distanciam os saberes escolares da formação ampla pretendida pela escola com base no propósito de que os(as) estudantes vivenciem experiências significativas de construção de saberes e capacidades práticas orientadas à inclusão e à participação social.

\section{DESENVOLVIMENTO CURRICULAR PARA ALÉM DE CISÕES ENTRE SABERES E CONTEXTOS EDUCATIVOS}

Toda a educação integral demanda por uma pedagogia integradora, mas há um tipo de educação integral em que ela é significada de modo particular. Nos referimos a uma perspectiva de pedagogia integradora em que a integralidade se faz pela ampliação do espaço e do tempo tomados desde uma concepção de certo modo inovadora. Um tempo que se amplia para além da sala de aula, compreendendo espaços nos quais a educação escolar se vê em presença de outras instituições de caráter socioeducativo, e que também se alarga, muitas vezes, para uma escola aberta aos finais de semana.

Um espaço que se abre para além da escola numa relação entreinstituições de educação e de assistência social, nem sempre formalizada e/ou legitimada, o que produz um espaço/tempo, por vezes, dilacerado. Outras vezes, esse espaço/tempo se amplia para outras modalidades de práticas como aquelas em que há o uso de espaço público: atividades culturais, lazer, esportivas, entre outras.

Por que uma pedagogia integradora para essa modalidade de educação integral que parece mais uma educação (des)integrada - pode se fazer pela articulação de práticas de educação escolar e não escolar? Uma pedagogia desse tipo e que pressupõe tamanha articulação precisa de uma intencionalidade rigorosa o que, por sua vez, pressupõe não somente o desenvolvimento curricular para além de cisões entre saberes e contextos educativos, mas a emergência de um campo de construção de diálogo, de debate sobre qual escola pública se quer oferecer para os piores situados socialmente. Isto porque, em geral, crianças e jovens adolescentes que frequentam escolas particulares possuem currículo ampliado, muitas vezes bilíngue o que já demanda por uma pedagogia integradora.

A pesquisa ativa desde o ano de 2018, realizada no estado do Rio Grande do Sul, numa parceria entre duas universidades, uma nacional e outra internacional, possui como problema de pesquisa a construção de conceitos alternativos de Educação Integral a partir de práticas que conjugam a educação escolar e práticas socioeducativas nas perspectivas da formação integral e do desenvolvimento social. Para tanto, são estudadas 4 escolas públicas de três regiões do estado - metropolitana de Porto Alegre (RMPA) (2), Serra Gaúcha (1) e Alto Uruguai (1), quase divisa com o Estado de Santa Catarina, que realizam e oferecem modalidades distintas de educação integral ${ }^{3}$.

3 Para fins da preservação do anonimato, conforme contratado em Termo de responsabilidade entre as instituições pesquisadoras e 
Por meio de metodologia da Educação Comparada Intranacional (FERREIRA, 2008, 2014), estamos verificando quais experiências que se realizam, como elas se manifestam, a partir de quais condições socioterritoriais formalizam ou não parcerias interinstitucionais e intersetoriais e como ocorre - se ocorre - uma educação integral/integradora, bem como quais as sinalizações quanto a emergência de uma pedagogia integradora.

0 estudo busca conhecer de forma mais aprofundada a realidade socioeconômica e cultural dos bairros onde se situam as escolas. Todos eles possuem em comum, em maior ou menor proporção, realidades de que nos permitem afirmar a presença de precariedades na infraestrutura, localização marginal em relação ao centro das cidades, altos índices de violência e ocorrência de crimes contra as pessoas, baixa oferta de educação infantil e, à exceção de uma escola que oferece educação básica em todos os níveis, as outras três estão situadas em territórios que não possuem escola de ensino médio.

Cada uma das escolas possui características peculiares e se alinham ao objetivo de reflexão deste ensaio, qual seja o de demarcar o significado conceitual para a expressão Pedagogia Integradora, assumindo-a como um mote para problematizar a ampliação dos tempos e espaços formativos em experiências de Educação Integral que articulam aspectos escolares e não escolares, de diferentes modos.

Para tanto, realizamos um estudo detalhado dos Projetos Políticos Pedagógicos (PPP) das 4 escolas buscando, entre outros, compreender quais concepções de educação, educação integral, comunidade, currículo e avaliação estão presentes no documento. No caso da educação integral os PPP também permitem relacionar essa modalidade de educação em articula com o território, rede de proteção, projetos socioassistenciais.

Importante ressaltar que os PPP estão atualizados e todos datam de 2016 com vigência até o presente ano de 2019. Em relação a oferta de práticas de educação integral as escolas apresentam modalidades distintas: E1 é uma escola municipal de turno único que oferece vagas de contraturno no Programa Movimentos e Vivências na Educação Integrada (MOVE) da Secretaria de Educação do Município e possui alunos/as que são atendidos no turno contrário em projetos socioeducativos em organizações sociais e projetos socioassistenciais governamentais.

Já E2 é uma escola municipal que se autodenomina de Educação Integral e em Tempo Integral desde a sua inauguração no ano de 2016. E3 é uma escola municipal de Educação Integral que a partir da extinção do PME desenvolveu um modelo próprio de educação em tempo integral, sendo a primeira e única escola de tempo ampliado no município. E4 é uma escola estadual de tipo CIEP, é a única escola de Educação Integral da cidade oferecendo o tempo integral desde o início da década de 1990.

Buscamos destacar quais concepções de Educação/Escola, Educação Integral, Currículo e Comunidade para refletir a relação entre saberes e contextos.

Educação/Escola: E1 busca em Delors (2002) e nos 'pilares aprender a conhecer, aprender a fazer, aprender a viver em conjunto e aprender a ser' fundamentos para uma ideia de escola em que educar é sinônimo de conhecer e implica o desenvolvimento da capacidade de refletir sobre a sociedade e suas demandas por transformações reais; domínio da escrita e da leitura; participação efetiva no mundo e no contexto local.

pesquisadas vamos nomear as escolas de E1, E2, E3 e E4. Sendo que E1 e E2 situam-se na RMPA, E3 no Alto Uruguai e E4 na Serra. 
E2 enfatiza a Educação como direito e não como privilégio, cuja materialidade é a formação do cidadão por meio da aprendizagem, da permanência e continuidade de estudos, enfatizando a presença de uma comunidade e de trabalhadores da educação convocados para impactar o território pela via da escola. E3 aposta num conceito de educação humanizadora cuja centralidade se volta à organização da convivência dos indivíduos matéria prima da constituição da vida pessoal e social.

E4 relaciona a escola a um time, onde todos têm um papel necessário para produzir avanços e vitórias. A concepção de escola é bastante metafórica relacionando também à ideia de conjunto musical, banda marcial, grupo de teatro, entre outros, onde destaca-se a ideia de obra de um grupo. A educação é apresentada enquanto um processo de desenvolvimento das capacidades intelectuais, morais e físicas do indivíduo.

A Educação Integral: para E1 é definida como uma oportunidade educativa que se materializa pela ampliação de tempos e espaços educativos realizada pelo compartilhamento da tarefa de educar entre profissionais de educação e de outras áreas, famílias, demais atores sociais. Contudo reforça que estas estratégias devem estar sob a coordenação e gestão da escola porque associada ao processo de escolarização.

Para E2 dimensiona a educação integral associada ao tempo integral, isto é, pressupõe a ampliação da jornada diária com a qualificação do tempo, mesclando a oferta de atividades complementares e acompanhamento individualizado a partir de uma organização curricular nova com vistas à formação integral. Essa deve considerar a relação dialógica e respeitosa entre os atores e o território a qual a escola pertence de forma a tecer uma rede de espaços sociais intra e extraescolares.

Já para E3 referencia a origem da proposta de educação integral em jornada ampliada ao Programa Mais Educação. Enfatiza a ampliação de tempos, espaços e conteúdo para uma aprendizagem significativa, contextualizada no horizonte de uma educação cidadã com foco na melhoria da qualidade de vida das pessoas. 0 desenvolvimento de diferentes dimensões do educando, a valorização de diferentes saberes e identidades sociais prevê também a expansão de experiencias educativas para além da escola enquanto atividades propostas pela gestão escolar.

E para E4 traz a concepção de educação integral colada à ideia de ocupação do tempo livre a partir de atividades educativas, entre elas, teatro, banda, canto e recuperação de crianças com déficit de aprendizagens. Associa a produção, profissionalização e o mundo do trabalho a partir de atividades em parceria.

O Currículo: E1 faz menção ao currículo de forma abrangente mais relacionado à sua teleologia, isto é, alude a organização curricular para contemplar a democratização do conhecimento, valorização de experiências, inclusão social e a diversidade cultural. E2 apresenta o currículo nas dimensões básica, complementar e comunitária. Na primeira, enfatiza as áreas de conhecimento disciplinar; na segunda aponta para um conjunto de atividades diferenciadas que privilegiam o desejo, as habilidades e as necessidades individuais dos sujeitos, no sentido de uma formação integral realizada por meio de uma educação integral em tempo integral. Apresenta na terceira dimensão a formação na perspectiva da realização pessoal e da construção de perspectivas futuras em diálogo permanente com espaços de aprendizagem não inclusos no ambiente escolar.

E3 aborda o currículo como um conjunto de saberes e experiências que se articulam entre si com vistas a elaboração de um currículo de educação integral em jornada ampliada por meio de diferen- 
tes linguagens (gestual, verbal, plástica, dramática e musical). E4 aponta à organização curricular estruturado em uma base comum prevista pela Diretrizes Curriculares Nacionais em interação com uma parte diversificada distribuída por áreas de conhecimento interdisciplinares.

A Comunidade: E1 concebe a comunidade integrada a escola por meio da oferta de eventos, por intermédio dos quais se constroem oportunidades para conquistar pais, amigos, familiares e a própria comunidade onde se insere a escola. E2, usando a expressão sentimento de pertencimento bilateral a escola entende a comunidade como aquela com quem a escola colabora pela presença do trabalho educativo num sentido amplo. A ideia de rede também compõe a concepção de comunidade a medida em que associa as organizações que atuam em prol do território como agentes em relação. 0 vínculo com a comunidade é valorizado pela dimensão da convivência que se produz em espaços de aprendizagem necessários a uma educação de tipo transformadora.

E3 tem na educação integral o objetivo de promover a integração escola-familia-comunidade apontando para a necessidade de ressignificar a função social da escola, bem como a de diferentes espaços e segmentos comunitários a partir do reconhecimento e da valorização dos diferentes saberes que coabitam o território. Por fim, referencia a Associação de Pais e Mestres (CPM) atuando em parceria com a comunidade escolar.

E4 novamente faz uso de metáforas cujo endereçamento ora aponta para a disputa, ora para a coesão onde a comunidade é fundamental para os resultados positivos dos alunos e da própria escola como referência de educação pública de qualidade na região onde se insere. Contudo a ideia de comunidade parece ficar restrita à comunidade escolar.

Interessante observar as contradições que emergem dos dados dos PPP das escolas. E1 que produz a integralidade do tempo pela concomitância das práticas escolares e não escolares parece reconhecer formalmente o seu Outro como ente educativo, contudo desde que recaia na escola a coordenação do processo de ensinar e aprender, inclusive cabendo a ela ser organizadora de uma ideia de comunidade.

E2, embora tenha todo o processo de educação integral em tempo integral centrado na instituição escolar possui uma relação muito próxima com a comunidade do entorno, reconhecendo nessa a possibilidade da sua prática efetiva para educar para a cidadania por meio de um mote que costura as diferentes dimensões curriculares que se dá pela formação que contempla a educação em direitos humanos.

E3 tem na ideia de protagonismo o fio que tece a relação com a comunidade, em especial com os serviços que podemos nomear de extraclasses. Isto porque a experiência da sua transformação em uma escola de tempo integral considera a relação construída quer pela oferta do extinto PME, quer por outras parcerias com organizações sociais ocorridas num passado recente.

E4 É uma escola de referência não somente na sua região como no estado. Constrói por meio da direção, corpo docente, técnicos científicos, pessoal de apoio e nas parcerias com empresas da cidade uma relação que sustenta um modelo de escola que é quase uma sobrevivente de uma proposta educacional que sucumbiu aos desmontes de governos estaduais no Rio de Janeiro e no Rio Grande do Sul. E que, portanto, para permanecer busca ser mais e mais referência de um modelo de escola que prima por excelentes resultados onde fazer parte significa estar entre os melhores, restando perguntar sobre quem acessa à escola. 


\section{MEDIAÇ̃̃ES DIDÁTICAS PARA CONSTRUIR UMA PEDAGOGIA INTEGRADORA NA EDUCAÇ̃̃O INTEGRAL}

Pensar a construção de uma Pedagogia Integradora requer considerar como as escolas em tempo integral podem dar lugar a relações dos sujeitos com os conhecimentos a partir de culturas de aprendizagem constituídas por mediações didáticas capazes de fazer com que enxerguem a complexidade do mundo e a si próprios como sujeitos complexos nesse mundo (MORIN, 2011). As mediações aqui propostas se organizam sob o entendimento da Didática como um campo de saberes e fazeres configurados na e pela práxis pedagógica que toma o ensino como prática social situada em contextos nos quais a formação humana é perpassada por fatores históricos, políticos, culturais e organizacionais.

Na perspectiva da multidimensionalidade, a Didática, segundo Franco e Pimenta (2016), envolve a reflexão crítica e propositiva em torno das relações que se estabelecem entre o ensino e a aprendizagem para além da instrumentalidade que, tradicionalmente, lhe é associada, pois, como também assinala Alvarez Méndez (2001, p. 135), ao não se limitar à criação de condições metodológicas para transmissão e reprodução de informações, a mediação didática deve buscar orientar os processos formativos “[...] para modos que exibam a complexidade dos conteúdos de conhecimento e não ajustá-los a fórmulas comprimidas de informação segura”.

As mediações didáticas na perspectiva da Pedagogia Integradora se pautam pelo pressuposto da complexidade para a compreensão das finalidades da aprendizagem na escola, contrapondo-se à ênfase no conhecimento como produto de especializações disciplinares, cuja expressão se dá pela dispersão, fragmentação e distanciamento curricular dos principais problemas cotidianos e globais que dinamizam a experiência dos sujeitos com o mundo ao seu redor. Embora o volume de conhecimento produzido pela ciência contemporânea seja cada vez maior e tenha alcançado uma amplitude gnosiológica em relação ao passado, quando o currículo escolar se conforma pela disciplinarização típica de uma tradição escolástica e cartesiana "[...] geralmente se fragmenta contextos, globalidades e complexidades" (MORIN, 2011, p. 134).

Esse modelo de conhecimento e currículo escolar dificulta o projeto de Educação Integral, uma vez que, fixada em uma codificação disciplinar, a aprendizagem se afasta de visões holísticas e sistêmicas fundamentais a uma compreensão mais ampla do mundo, de suas relações, contradições e possibilidades de mudança. Por isso, as mediações didáticas da Pedagogia Integradora no desenvolvimento curricular devem possibilitar que os(as) estudantes acessem conhecimentos sistematizados para criarem e recriarem relações entre o que já conhecem e novas oportunidades de aprendizagem sem ignorarem a experiência concreta, que é particular e social ao mesmo tempo, como núcleo central para processos de problematização, pesquisa, reflexão e sistematização de saberes e habilidades.

Visto como um dispositivo que cria relações e integração de saberes e experiências diversas, o currículo, na perspectiva da Pedagogia Integradora, concorre à promoção de capacidades de compreensão e ação individuais e coletivas, na interface entre autonomia e colaboratividade, com foco em questões importantes que sirvam para ampliar os horizontes de reflexão e engajamento protagonista 
e não em planos sequenciais de conteúdos que refletem um “[...] modelo pedagógico tradicional de caráter meramente instrutivo, em que os professores centralizam todo o protagonismo e os alunos são os grandes ausentes" (CARBONELL, 2016, p. 192).

Nesse sentido, as mediações didáticas traduzem um enfoque globalizador cujas implicações na organização de situações de aprendizagem na escola em tempo integral vão desde a incorporação de pautas curriculares interessadas nos cotidianos vividos pelos estudantes dentro e fora da sala de aula, a cooperação como incentivo às relações de construção social do conhecimento em suas dimensões éticas e políticas, à superação da pedagogia escritocêntrica e verbalista e à avaliação mais centrada em percursos individuais do que em resultados obtidos sob a égide da cultura de testagem e padronização de desempenho.

Carbonell (2016), quando discorre sobre as marcas comuns das diferentes propostas didáticas do que denomina de Pedagogia do Conhecimento Integrado, aponta que a visão de escola que se busca concretizar se assenta em uma prática arraigada de democracia radical como meio de fomentar a participação ativa dos(as) estudantes na tomada de decisões e definição de responsabilidades; na concepção da escola como uma comunidade de aprendizagem aberta em que diferentes experiências dentro e fora da sala de aula são objeto de intercâmbios; e na busca pela criação de um espaço que estimule continuamente o desejo de pesquisar, aprender, criar e se comunicar dos(as) alunos(as).

Quando se concebe que o ensino se estrutura como mediação didática para favorecer à construção compartilhada do conhecimento e a formação de aptidões necessárias para a transformação de realidades individuais e coletivas, opera-se com a concepção socioconstrutivista de aprendizagem contextualizada, ou seja, que "a aprendizagem é realizada de maneira situada [...] o contexto em que uma pessoa aprende tem um papel fundamental naquilo que aprende” (HERNÁNDEZ; VENTURA, 1998, p. 94).

A qualidade da aprendizagem se vincula à qualidade das interações e das experiências nas quais se dão. Assim, cabe indagar, que estratégias de mediação didática podem ser mobilizadas para favorecer a emergência desses contextos e atender à concepção de Educação Integral, qual seja, o pleno desenvolvimento dos(as) estudantes por meio de experiências dentro e fora da escola que enriqueçam seus sentidos sobre si mesmos e suas realidades.

Cabe aqui destacar que experiência é entendida no sentido apresentado por Larrosa Bondía (2002, p. 21) para o qual “[...] é o que nos passa, o que nos acontece, o que nos toca. Não o que se passa, não o que acontece ou o que toca. A cada dia se passam muitas coisas, porém, ao mesmo tempo, quase nada nos acontece". A assertiva sobre experiência desse autor carrega uma potência por permitir problematizar se o alargamento do tempo escolar nas escolas de tempo integral ou jornada ampliada implica na ampliação ou enriquecimento de experiências formativas para os(as) estudantes.

Evidentemente, entende-se que não à equivalência entre esses dois fatores, tempo de escolarização e qualidade das experiências. Daí deriva a necessidade de buscar respostas à indagação didática anteriormente formulada. Por se constituir em um território plural de aprendizagens multidimensionais, a escola de Educação Integral em tempo integral, as experiências formativas didaticamente mediadas ocorrem dentro e fora da sala de aula, alargando a ideia de espaço pedagógico para onde seja possível criar possibilidades de subjetivação e produção de saberes, incluindo a comunidade, o bairro e a cidade em que a escola está inserida. 
Esse aspecto é especialmente relevante porque o fato de estar entre sete e nove horas em uma escola com atividades regradas sob a dinâmica disciplinar de sala de aula pode despertar nos(as) estudantes desinteresse e adesão pouco significativa às atividades propostas. Eventualmente, as escolas proporcionam às turmas passeios pedagógicos ou estudos de campo que levam para outros territórios, mas o currículo não transita neles, pois se mantém centrado em disciplinas e materiais instrucionais que não se integram aos textos culturais produzidos nos espaços educativos não escolares.

Quando se concebe a cidade ou a comunidade como entornos curriculares atenta-se para a dimensão de que as experiências com o espaço e as suas formas socioculturais de uso manifestam sentidos que perfazem determinados modos de subjetivação e significação da convivência coletiva e que o desafio da escola é construir caminhos didáticos para "[...] transformar essa experiência social e individual em uma prática experiencial, questionadora e reflexiva, que permita construir saberes críticos e sistematizar propostas de intervenção e mudança” (BONAFÉ, 2016, p. 161). A expansão dos tempos e espaços formativos da escola é uma oportunidade para situar o conhecimento em contextos diversificados de criação e uso e a cidade ou a comunidade são lugares para reconhecer currículos culturais em processo contínuo de (des)construção.

Na perspectiva da Pedagogia Integradora, as mediações didáticas são orientadas pela crença radical no potencial de aprendizagem de todos(as) os(as) estudantes e reconhecem que há estilos e expressões de aprendizagem diferentes, de modo que se constitui como uma habilidade de ensino o uso de diferentes recursos educativos visuais, auditivos e cinestésicos referenciados no olhar atento e sensível do(a) professor(a) às necessidades, interesses e aptidões individuais para maximizar potenciais dos(as) estudantes e na compreensão das inteligências múltiplas.

A condição diferenciada do(a) estudante diante do objeto de conhecimento ou habilidade proposto pela escola demanda o uso de estratégias avaliativas que possibilitem, ao(à) docente, "entender o ponto em que cada aluno está em sua aprendizagem, proporcionar feedback de qualidade e planejar os próximos passos com objetivos compartilhados" (BRIGHOUSE; WOODS, 2016, p. 177).

Trata-se de perceber o(a) estudante em sua integralidade e criar possibilidades didáticas de acompanhamento individual que estimulem a co-responsabilização por seu processo de aprendizagem e o encorajamento ao engajamento ativo em formas de estudo e pesquisa que atendam ao modo como pode aprender mais e melhor. Algumas dessas possibilidades didáticas consistem em tutorias e estudos orientados conectados ao trabalho de acompanhamento e orientação do processo de aprendizagem em sala de aula.

O protagonismo do(a) estudante na construção dos seus percursos de aprendizagem é estimulado e fortalecido por meio de estratégias didáticas que favoreçam o aprender a aprender, cujo sentido reside no envolvimento ativo em formas de produção e aquisição de saberes e formação de habilidades fundamentadas: a) na escolha e aplicação consciente de diferentes maneiras para aprender; b) na colaboratividade presente em redes de troca de saberes e experiências compartilhadas com os(as) outros(as); c) no desenvolvimento de atitudes positivas consigo e com as outras pessoas; $d$ ) na reflexão crítica sobre 0 seu projeto de vida no contexto social e político que o cerca para o exercício da cidadania.

Do ponto de vista didático, a Pedagogia Integradora pode ser traduzida mais autenticamente por meio das metodologias ativas de ensino-aprendizagem, pois se o objetivo da escola é aportar condições 
para que os(as) estudantes criem e recriem saberes com base no conhecimento historicamente acumulado em diálogo com a complexidade que configura os cotidianos vividos como fonte epistemológica, as situações formativas em Educação Integral são cenários em que o(a) aluno é posicionado como sujeito autônomo de relações colaborativas para criação e mobilização de saberes, habilidades e atitudes.

Por metodologias ativas entende-se um amplo leque de estratégias didáticas que promovem a condição autoral, construtiva e responsiva de estudantes na relação com os conhecimentos, vinculando-os a aspectos significativos do contexto em que se constituem cultural e socialmente de modo a estimular o pensamento crítico e inovador e atitudes colaborativas na resolução de problemas (MEIRIEU, 1998).

Com isso, os parâmetros usados para determinar a qualidade didática das mediações na Educação Integral não decorrem de uma concepção utilitarista do que os(as) estudantes devem aprender para reproduzir em avaliações externas, sugerindo uma didática do "conteudismo".

Na lógica de uma Pedagogia Integradora, como se argumenta neste texto, a qualidade didática se refere às condições e recursos significativos para transposição/produção de conhecimentos relevantes à formação integral do(a) aluno(a)-cidadão(ã)-pessoa e para a consolidação da escola como lugar plural de aprendizagens relacionais e sociais, envolvendo as dimensões socioafetivas e políticas que constituem o desenvolvimento humano e, particularmente, da vontade humana para a mudança social. Isso implica, inclusive, em um trabalho de investigação didática levado a cabo pela escola para identificar e incorporar modos e relações de aprendizagem constituídas em outros territórios educativos que sirvam para ampliar o seu próprio repertório metodológico.

\section{CONSIDERAÇÕES FINAIS}

A Pedagogia Integradora representa uma concepção teórico-metodológica que investe no reconhecimento de diferentes possibilidades de conexão entre saberes que constituem o currículo escolar com base na problematização das fronteiras epistemológicas e culturais que separam o território escolar de outros espaços e dinâmicas sociais de aprendizagem. Assim, se sustenta em um fundamento didático que concebe a mediação docente como trabalho de criação reflexiva e coletiva de oportunidades e recursos formativos que engajem os(as) estudantes em atividades que, em uma perspectiva freiriana, (re) aprendem a ler o mundo em suas formas de representação dentro e fora da escola.

Uma modalidade de Educação Integral, verdadeiramente integradora, na escola pública, se constrói pela participação social e por intermédio de práticas intersetoriais. Talvez a presença dos binômios integração/desintegração, escolar/não escolar nos coloque mediante a concepção de uma "desterriorização" da sala de aula. Mas em que medida isto ocorre? Quais são as condições materiais para que tal modalidade educativa produza tamanha ruptura com um modelo de educação hegemônico, altamente prescritivo, cujos resultados são medidos por métricas demasiado disciplinares e que desconsideram saberes prévios, cultura popular e uma formação comunitariamente referenciada? São indagações que ampliam o debate e desdobram sua continuidade.

As sinalizações didáticas feitas neste texto não prescindem de um exame crítico das condições 
concretas que as escolas possuem para efetuar a oferta de ensino em tempo integral ou jornada ampliada, que vão desde entraves estruturais à dificuldades de gestão e valorização do trabalho docente, passando pela definição do sentido da Educação Integral em uma sociedade na qual a construção da democracia e da justiça social é um desafio perene.

Como afirma Cavaliere (2009, p. 61), a escola se constitui na dinâmica da sociedade e a constitui como um ponto central de uma rede de instituições com as quais se integra na complexa tarefa de educar. Isso exige que a função da escolarização seja definida na direção do seu “[...] fortalecimento como local público destinado a garantir o desenvolvimento e o bem-estar de todas as crianças e jovens brasileiros.

Ao lado de desafios políticos e financeiros, a ampliação e consolidação da Educação Integral em tempo integral é fundamental que as experiências produzidas em diferentes cenários sociais e institucionais sejam inspiradas por uma Pedagogia Integradora como concepção teórico-metodológica que investe no reconhecimento de diferentes possibilidades de conexão entre saberes que constituem o currículo escolar com base na problematização das fronteiras epistemológicas e culturais que separam o território da escola de outros espaços e dinâmicas sociais de aprendizagem.

\section{REFERÊNCIAS}

ALVAREZ MÉNDEZ, Juan Manuel. Entender la didáctica, entender el curriculum. Madrid: Miño y Dávila, 2001.

BONAFÉ, Jaume. Na escola, o futuro já não é o passado, ou é. Novos currículos, novos materiais. In: ZABALA, Antoni et al. Didática geral. Porto Alegre: Penso, 2016. p. 149-164.

BRASIL, Lei n. 13.005, de 25 de junho de 2014. Aprova o Plano Nacional de Educação - PNE e dá outras previdências. Diário Oficial da União, Brasília-DF, p. 1, 26 de junho de 2014. Seção 1 (ed. Extra).

BRASIL. Constituição da República Federativa do Brasil de 1988. Disponível em: http://www. planalto.gov.br/ccivil_03/constituicao/constituicaocompilado.htm. Acesso em: 9 set. 2019.

BRASIL. Lei 9.394 de 20 de dezembro de 1996. Estabelece Diretrizes e Bases da Educação Nacional. Disponível em: http://www.planalto.gov.br/ccivil_03/LEIS/L9394.htm. Acesso em: 9 set. 2019.

BRASIL. MEC. Educação Integral: texto referência para o debate nacional. Brasília: MEC, SECAD, 2009. Disponível em: http://portal.mec.gov.br/dmdocuments/cadfinal_educ_integral.pdf. Acesso em: 9 set. 2019.

BRIGHOUSE, Tim; WOODS, David. Ensino e aprendizagem. In: ZABALA, Antoni et al. Didática geral. Porto Alegre: Penso, 2016. p. 165-192. 
CAMARGO, Rosa Maria Bortolotti; SARTURI, Rosane Carneiro; TREVISAN, Mônica de Souza. Educação Integral na região sul do Brasil. Revista Retratos da Escola, Brasília, v. 13, n. 25, p. 219237, jan.-maio 2019. Disponível em: http//www.esforce.org.br. Acesso em: 9 set. 2019.

CARBONELL, Jaume. Pedagogias do século XXI: bases para a inovação educativa. 3. ed. Porto Alegre: Penso, 2016.

CAVALIERE, Ana Maria. Escola de tempo integral versus alunos em tempo integral. Em Aberto, Brasília, v. 22, n. 80, p. 51-64. Disponível em: http://emaberto.inep.gov.br/index.php/emaberto/ article/view/2220. Acesso em: 9 set. 2019.

DELORS, Jacques. Educação: um tesouro a descobrir. Relatório para UNESCO da comissão internacional sobre educação para o século XXI. São Paulo: Cortez, 2002.

FERREIRA, Gomes António. O sentido da educação comparada: uma compreensão sobre a construção de uma identidade. Educação Porto Alegre, v. 31, n. 2, p. 124-138, maio-ago. 2008. Disponível em: http://revistaseletronicas.pucrs.br/ojs/index.php/faced/article/view/2764. Acesso em: 9 set. 2019.

FERREIRA, Gomes António. Os outros como condição de aprendizagem: desafio para uma abordagem sociodinâmica da Educação Comparada. Educação Unisinos, v. 18, n. 3, p. 220-227, set.-dez. 2014. Disponível em: http://revistas.unisinos.br/index.php/educacao/article/view/ edu.2014.183.01. Acesso em: 9 set. 2019.

FRANCO, Maria Amélia Santoro; PIMENTA, Selma Garrido. Didática multidimensional: por uma sistematização conceitual. Educ. Soc., Campinas, v. 37, n. 135, p. 539-553, abr.-jun., 2016. Disponível em: http://www.scielo.br/pdf/es/v37n135/1678-4626-es-37-135-00539.pdf. Acesso em: 9 set. 2019.

GADOTTI, Moacir. Educação integral no Brasil: inovações em processo. São Paulo: Editora e Livraria Instituto Paulo Freire, 2009.

\section{HERNÁNDEZ, Fernando; VENTURA, Montserrat. A organização do currículo por projetos de}

trabalho: o conhecimento é um caleidoscópio. 5. ed. Porto Alegre: Artes Médicas, 1998.

LARROSA BONDIA, Jorge. Notas sobre a experiência e o saber de experiência. Rev. Bras. Educ., Rio de Janeiro, n. 19, p. 20-28, abr. 2002. Disponível em: http://www.scielo.br/pdf/rbedu/n19/n19a02. pdf. Acesso em: 9 set. 2019. 
LECLERC, Gesuína Fátima Elias; MOLL, Jaqueline. Educação integral em jornada diária ampliada: universalidade e obrigatoriedade? Em Aberto, Brasília, v. 25, n. 88, p. 17-49, jul.-dez. 2012.

Disponível em: http://emaberto.inep.gov.br/index.php/emaberto/article/viewFile/2583/2493. Acesso em: 9 set. 2019.

MEIRIEU, Philippe. Aprender... sim, mas como? 7. ed. Porto Alegre: Artmed, 1998.

MOLL, Jaqueline. Reiventar a escola dialogando com a comunidade e com a cidade: novos itinerários educativos. Pátio: Revista Pedagógica, Porto Alegre, ano VI, n. 24, p. 58-61, jan. 2003.

MORIN, Edgar. Os sete saberes necessários à educação do futuro. São Paulo: Cortez; Brasília, DF: UNESCO, 2011. 
1 Doutor em Educação; Professor Permanente do Programa de Pós-Graduação em Educação da Universidade Federal da Paraíba; Líder do Grupo de Estudos e Pesquisas em Pedagogia, Trabalho Educativo e Sociedade (GEPPTES/UFPB); Pesquisador do Grupo de Estudos e Pesquisas em Educação Não Escolar - FEEVALE.

E-mail: leonardosevero@ce.ufpb.br

2 Doutora em Educação; Professora do Programa de Pós-Graduação em Diversidade Cultural e Inclusão Social da Universidade Feevale; Líder do Grupo de pesquisa de Estudos e Pesquisas em Educação Não Escolar - FEEVALE; Pesquisadora do Grupo de Estudos e Pesquisas em Pedagogia, Trabalho Educativo e Sociedade (GEPPTES/ UFPB); Produtividade em Pesquisa - CNPq.

E-mail: dinora@feevale.br

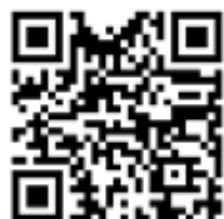

A autenticidade desse artigo pode ser conferida no site https://periodicos. set.edu.br

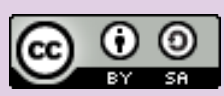

Este artigo é licenciado na modalidade acesso abertosob a Atribuição-Compartilhalgual CC BY-SA

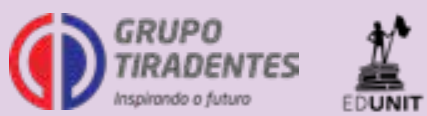

